\title{
Uma análise da leitura de Popper acerca do antiteoricismo de Bacon
}

\author{
AN ANALYSIS OF POPPER INTERPRETATION ABOUT BACON ANTITEORICISM
}

Helton Lima Soares ${ }^{1}$

1 Graduando em Licenciatura em Filosofia e membro do Grupo de Pesquisa em Filosofia da Ciência da Universidade Federal do Pará (UFPA) Email: heltondelimasoares@gmail.com Lattes: http://lattes.cnpq.br/1216029247820826 Orcid: http://orcid.org/0000-0002-6267-476X

RESUMO: O presente artigo tem como objetivo analisar a interpretação de Popper acerca de um suposto antiteoricismo, que se manifesta na ideia de purificação da mente e na defesa da observação como ponto inicial da ciência, em Francis Bacon. Popper considera que tal posição antiteórica, a que deu o nome de "observacionismo", supervaloriza o papel da observação no método científico. Procuramos discutir se Bacon realmente assume tal posição e em quais circunstâncias a leitura popperiana é possível. Nossa hipótese é de que o filósofo inglês não pode ser considerado um antiteoricista e, portanto, um defensor do empirismo ingênuo. Dessa maneira, iremos expor a posição de Popper e depois contestá-la com auxílio de comentadores especializados na teoria baconiana.

Palavras-chave:Observacionismo. Indução. Ídolos.

ABSTRACT: This article is aimed at analysing Popper's interpretation about a supposed antiteoricism, which manifests itself in Francis Bacon's idea of purification of mind and defense of observation as the starting point of science. Popper considers that such antitheoretical position, wich he gaves the name of "observationalism", overvalues the role of observation in scientific method. We seek to discuss if Bacon really assumes such position and in which circumstances the Popperian interpretation is possible. Our hypothesis is that the English philosopher cannot be considered a antitheoretical person and, therefore, a supporter of naive empiricism. Thus, we will expose Popper's position and then contest it with the help of commentators specialized in Baconian theory.

Keywords: Observationalism. Induction. Idols.

\section{Introdução}

Em sua obra O Mito do Contexto, especificamente no capítulo "Ciência: problemas, objetivos, responsabilidades", Karl Popper aponta Francis Bacon como defensor de um dogma antiteórico que supervaloriza os méritos da observação e denuncia os vícios da razão. A este dogma Popper deu o nome de "observacionismo", considerando-o como uma tentativa de fundamentação do método científico e do critério de demarcação proposto pelo Lorde Verulâmio': a indução. Este suposto dogma, na visão do filósofo, tenta fundamentar também a religião secularizada da ciência, da qual Bacon é o profeta.

Pretendemos neste artigo analisar se de fato há em Bacon uma posição antiteórica conforme afirma Popper. Responder à questão se há ou não defesa de um antiteoricismo em Bacon não é tarefa simples, pois alguns aforismos de sua principal obra sobre o método, Novum Organum ou Verdadeiras Indicações Acerca da Interpretação da Naturęa, parecem confirmar a interpretação popperiana, entretanto uma análise mais atenta da obra permite pôr em xeque tal interpretação.

${ }^{1}$ Alguns estudiosos de Bacon se referem ao filósofo dessa forma. 
Consideraremos que Bacon não é um empirista ingênuo ${ }^{2}$, portanto, um antiteoricista como assegura Popper. Para sustentarmos nossa posição, tomaremos como objeto principal de nossa investigação a obra Novum Organum, como também escritos de estudiosos de Bacon, como Rossi e Horton, que afirmam haver uma busca pelo equilíbrio entre razão e observação na teoria da ciência de Bacon.

Nossa análise será desenvolvida em dois tópicos, a saber: o primeiro concerne ao "dogma antiteórico de Bacon à luz de Popper", no qual apresentaremos a crítica popperiana ao "observacionismo", e o segundo refere-se às “contestações à interpretação de Popper”, tópico em que se argumentará que Bacon não assumiu uma atitude ingênua perante a experiência.

\section{O dogma antiteórico de Bacon à luz de Popper}

Na obra O Mito do Contexto, Popper considera Bacon o fundador de uma corrente intelectual religiosa ou semirreligiosa, que substituiu a ideia de "Deus" pela ideia de "Natureza" (POPPER, 2009, p. 142). Este movimento julgava que a Natureza, tal como Deus, estava presente em todas as coisas e que seria tarefa da ciência empírica encontrar a natureza das mesmas. Para que esta tarefa fosse possível, as impurezas da mente deveriam ser extirpadas de modo que se possa "ler o Livro da Natureza" sem distorcê-lo (POPPER, 2009, p. 144), ou seja, observar os fenômenos naturais de forma cuidadosa e atenta e registrálos fielmente sem qualquer deformação intelectual, pois, só assim, se teria acesso ao verdadeiro conhecimento da natureza.

Para o filósofo, é essa investigação que busca purificar a mente e que se restringe a observar os fenômenos e registrá-los, sem um norteamento de qualquer hipótese, que se configura como o dogma antiteórico de Bacon, que denominamos, neste trabalho, de antiteoricismo. Diz ele: "O dogma baconiano a que me refiro enuncia os méritos supremos da observação e o vício da especulação teorizante. Chamarei a este dogma, resumidamente, 'observacionismo”' (POPPER, 2009, p. 144).

Assim, o observacionismo se revela na supervalorização da observação e da indução, não apenas enquanto método da ciência, mas também, enquanto critério de demarcação científica, uma vez que estas últimas nos permitem distinguir a "nova ciência" de um lado e a velha teologia e filosofia de outro (POPPER, 2009, p. 143). É precisamente contra essa concepção que Popper dirige sua crítica. Podemos dizer que, para o filósofo, tal antiteoricismo advém, em última análise, do método indutivo visto como o verdadeiro procedimento que a ciência deve utilizar para conhecer as formas da natureza, e é em nome dele que é proposto a purificação da mente. Enfatizamos, entretanto, que não há uma dispensabilidade da teoria no método indutivo de Bacon, mas que o filósofo prioriza a observação.

Assim, ao subordinar o conhecimento da natureza à observação atenta dos fenômenos, Bacon parece acreditar na ideia de uma verdade evidente, doutrina otimista e amadora que pregava a verdade como sempre acessível, bastando um breve esforço para reconhecê-la na natureza (POPPER, 2008, p. 33-35). Deste modo, se o Livro da Natureza revela facilmente sua verdade, ou seja, suas formas, seria mais sensato voltar-se a ele com a mente purificada, isto é, livre de preconceitos. A este respeito, Popper comenta:

O novo método de Bacon, que recomenda como o verdadeiro caminho para o conhecimento [...], é o que se segue. Devemos purificar nossa mente de todos os preconceitos, de todas ideias pré-concebidas, de todas as teorias - de todas essas superstições, ou "ídolos", que a religião, a filosofia, a educação ou a

\footnotetext{
2 Será usado como sinônimo de "empirismo ingênuo" o termo "puro empirismo".
} 
tradição possam ter-nos transmitido. Quando tivermos purificado as nossas mentes de preconceitos e impurezas, podemos aproximar-nos da Natureza. E a Natureza não nos induzirá em erro. Pois não é ela que nos induz ao erro, mas apenas os nossos próprios preconceitos, as impurezas das nossas mentes (POPPER, 2009, p. 144).

Popper chama atenção para um "falso"método especulativo, denunciado por Bacon, que conduz aos preconceitos ouídolos, responsáveis por "leituras" precipitadas da natureza.Vale ressaltar que Bacon, de fato, faz uma distinção entre o queintitulou de antecipações da naturęa e interpretação da naturezano aforismo XXVI do Livro I, do Novum Organum. As antecipações concernem ao método da tradição a qual Bacon se opunha, considerando-a como arriscada e prematura, e a interpretação à sua nova concepção de ciência capaz de alcançar a verdade ascendendo gradualmente por meio de fatos observacionais.

Os ídolos são, assim, os responsáveis pela prejudicial antecipação teóricada natureza, pois deturpam a mente e a impedem de observar a natureza como ela realmente é. É o que nos diz Bacon, no Novum Organum:

Os ídolos e noções falsas que ora ocupam o intelecto humano e nele se acham implantados não somente o obstruem a ponto de ser difícil o acesso da verdade, como, mesmo depois de seu pórtico logrado e descerrado, poderão ressurgir como obstáculo à própria instauração das ciências, a não ser que os homens, já precavidos contra eles, se cuidem o mais que possam (BACON, 1999, p. 39).

Esses ídolos, no Novum Organum, são apresentados como sendo de quatro tipos distintos: ídolos da tribo, ídolos da caverna, ídolos do foro e ídolos do teatro. Enas obras De Augmentis Scientiarum e Distributio Operis, Bacon classifica esses ídolos em inatos e adventícios. Dessa maneira, os ídolos da tribo, da caverna e do foro são inerentes à natureza humana, enquanto que os ídolos do teatro são adquiridos (ROSSI, 2006, p. 41-42).

O primeiro diz respeito à natureza humana enquanto coletivo ou espécie. Trata-se dos preconceitos responsáveis pelo julgamento inapropriado das coisas (pelos sentidos), pois o intelecto humano equipara-se "a um espelho que reflete desigualmente os raios das coisas e, dessa forma, as distorce e corrompe" (BACON, 1999, p. 40). O segundo corresponde ao humano enquanto indivíduo, isto é, ao seu processo de formação educativa, psicológica, social, etc., que desvia a luz da natureza e a interpreta a partir de seu ponto de visto, de sua própria “caverna”(BACON, 1999, p. 40).

O terceiro é ocasionado pelas interações sociais possibilitadas pelo uso da linguagem/discurso. Para Bacon, palavras são apenas palavras, porém uma vez usadas de modo descompromissado e confuso, no âmbito público, atrapalham o avanço do conhecimento (BACON, 1999, p. 41). O quarto é composto pelas filosofias criadas pela tradição (sofística, empírica e supersticiosa), cheias de noções vulgares, que se assemelham a fábulas e a obras teatrais(BACON, 1999, p. 48-49).

Na obra Novum Organum, na qual Bacon omite a separação dos ídolos em inatos e em adquiridos, ele propõe no aforismo LXVIII, do Livro I, que todos os ídolos sejam expurgados da mente do cientista a fim de tornar mais seguro o processo de descoberta das formas da natureza:

Já falamos de todas as espécies de ídolos e de seus aparatos. Por decisão solene e inquebrantável todos devem ser abandonados e abjurados. O intelecto deve ser liberado e expurgado de todos eles, de tal modo que o acesso ao reino do homem, que repousa sobre as ciências, possa parecer-se ao acesso ao reino dos céus, ao qual não se permite entrar senão sob a figura de criança. 
Deste modo, tal recomendação para se eliminar todos os ídolos parece dar razão a Popper quando este considera que há um dogma antiteórico em Bacon e endossa a ideia deque "a especulação e as teorias são más e constituem a causa de todo o erro" (POPPER, 2009, p. 145).

Popper, opondo-se a tais indicações, considera que uma mente sem qualquer teoria é uma mente vazia, o que é algo improvável, pois sempre se opera com teorias, mesmo que inconscientemente. Portanto, a ideia de uma mente purificada é errônea e ingênua (POPPER, 2009, p. 148). Mesmo porque qualquer observação é precedida por uma seleção: é necessário ter em mente um ponto de vista,ou seja, é necessário saber o que sequer observar, uma vez que sem uma seleção prévia de um problema, uma tarefa, um objeto, etc., o cientista não saberia o que de fato estaria procurando (POPPER, 2008, p. 76). Dessa maneira, fica clara a posição contrária de Popper com relação à ideia de purificar a mente para prepará-la à observação perceptual da natureza.

No entanto, a concepção antiteórica de Bacon, no entender de Popper, não se resume apenas à eliminação dos ídolos de modo a se ter uma mente purificada, ela se apresenta, também, no próprio método indutivo-observacional proposto pelo filósofo. Seu método indica um processo sistemático e gradual de coleta e interpretação de dados retirados da natureza. Podemos entendê-lo como um caminho que parte da experiência (experientia litterata) para o axioma (teoria) e deste para novas experiências (experientia crucis) (BACON, 1999, p. 109). Ao esclarecer como o método deverá ser utilizado para o conhecimento da natureza, Bacon propõe as seguintes etapas: 1) coleta dos dados da natureza e sua organização; 2) interpretação desses dados e formulação de um axioma provisório; e 3) teste do axioma formulado.

$\mathrm{Na}$ primeira etapa, após administrar e eliminar os ídolos de sua mente, o cientista registra os dados que observa da natureza tendo em vista três possíveis ordenações: aspresenças do fenômeno, suas ausências e suas variâncias. A primeira corresponde à tábua de investigação das presenças (BACON, 1999, p. 111), a segunda à tábua das ausências (BACON, 1999, p. 111) e a terceira à tábua das comparações (BACON, 1999, p. 120). Com essa sistematização, é possível haver certa segurança que impede a dispersão do intelecto no momento da coleta dos dados (história natural).

A próxima etapa consiste na análise dos dados coletados a fim de eliminar as noções confusas que se apresentam como explicativas do fenômeno e de se formular o que Bacon chamou de primeira vindima, isto é, um primeiro axioma, de caráter provisório, que explica de forma geral o fenômeno estudado (BACON, 1999, p. 131). Vale ressaltar que a primeira vindima tem maiores chances de se revelar como falsa, uma vez que a procura pela verdadeira causa exige eliminação das explicações que não condizem com as experiências finais.

A última etapa diz respeito aos experimentos planejados a partir do axioma de primeira ordem, que podemos entender como a primeira hipótese de caráter universal. A criação de novos experimentos, ou novas experiências, tem como objetivo pôr a prova o axioma a fim de confirmar sua veracidade ou falsidade.Nesta etapa, Bacon propõe as chamadas instâncias prerrogativas, 27 (vinte e sete) no total, que são técni$\mathrm{cas}^{3}$ experimentais para testar as teorias.

Face ao método indutivo proposto por Bacon, as críticas de Popper são de duas naturezas: a primeira, diz respeito à prioridade temporal da observação frente à teoria, e a segunda, ao próprio método indutivo enquanto procedimento de descoberta e justificação de fatos.

Popper chamou de observacionismo a valorização que Bacon concede a observação perante a teoria. O filósofo austríaco vê nessa atitude uma hostilização às formas de pensamento teórico (POPPER,

3 Tais técnicas são descritas nos aforismos XXII e LI do Livro II do Novum Organum. 
2009, p. 145). Contrapondo-se a essa concepção, a explicação popperiana é de que o cientista que almeja conhecer a natureza é sempre guiado por um ponto de vista: seu aporte teórico, o problema que está tentando resolver, suas hipóteses, "seu quadro de referências, seu 'horizonte de expectativas", como explicado na obra Conjecturas e Refutações (2008 p. 76-77). Todas essas possíveis "expectativas do momento" tornam a observação seletiva. Na obra A Lógica da Pesquisa Cientifica o filósofo esclarece:

A ciência não pode ser destilada de experiências sensoriais não interpretadas, independentemente de todo o engenho usado para recolhê-las e ordená-las. Ideias arriscadas, antecipações injustificadas, pensamento especulativo, são os únicos meios de que podemos lançar mão para interpretar a natureza: nosso único "organon”, nosso único instrumento para apreendê-la (POPPER, 2013, p. 244).

A crítica popperiana vai de encontro à concepção empirista tradicional, da qual Bacon faz parte (DIAS, 1992, p. 83-84), de que a experiência perceptual é o material primeiro do conhecimento científico. Por mais que se possa argumentar que a teoria tem um espaço fundamental no método de Bacon, sendo necessária, por exemplo, para construir os experimentos finais que revelam sua veracidade ou falsidade, ainda assim a ciência inicia pela observação direta da natureza. Aí se encontra o cerne da crítica popperiana.

Com relação à segunda crítica, Popper não considera a indução um método apropriado de descoberto e justificação de fatos. Na sua obra A Lógica da Pesquisa Cientifica (2013, p. 27-29), desenvolve uma argumentação a fim demostrar a insustentabilidade do método indutivo. Apesar de, nessa obra, não deixar claro que suas críticas são direcionadas a concepção de Bacon, pode-se entender que, por ele defender a indução, tais críticas têm, também, por alvo sua concepção.

A principal crítica que Popper faz a indução diz respeito a sua justificação lógica. Neste sentido, não há como se inferir leis universais a partir de enunciados singulares, uma vez que, independentemente da quantidade de observações, nunca se poderáconcluir que todos os casos ocorreram da mesma forma que os observados. Ademais, a verdade de uma lei universal não pode ser reduzida a verdade de enunciados de experiência, pois estes só podem garantir a verdade do que foi observado e não a verdade dos casos não observados, que estão incluídos em uma lei universal (POPPER, 2013, p. 27-29). A partir desses, e outros argumentos, Popper considera a indução insustentável.

Entendemos que as duas críticas apresentadas ao método de Bacon atingem diretamente sua concepção, pois, conforme mostramos anteriormente, o filósofo inglês faza defesa da observação enquantoprimeiro passo para o desenvolvimento de conhecimentos científicos seguros e da indução enquanto o caminho para tal construção.

Procuramos aqui apresentar no que consiste a posição antiteórica de Bacon conforme a leitura de Popper, que o considera um empirista ingênuopor defender que a ciência parte da observação da natureza a partir de uma mente purificada. Como mostramos, há alguns aforismos que, tomados de forma isolada, parecem confirmar a interpretação popperiana acerca da teoria de Bacon. Contudo, apenas estes aforismos são suficientes para sustentar talinterpretação? Bacon pode ser considerado um puro empirista? Apresentaremos, a seguir, algumas concepções acerca da obra de Bacon que divergem da interpretação de Popper.

\section{Contestaçõesà interpretação de Popper}

Alguns estudiosos do Lorde Verulâmio, como Paolo Rossi e Mary Horton, discordam veemente- 
mente da interpretação dePopper. Ambos argumentam que Bacon não advoga um empirismo ingênuo, pois sabia dos impasses de defender a ideia de purificação da mente e da importância da teoria no método científico. E acrescentam que ele, também,não pode ser considerado umantiteoricista, pois assumiu uma posição crítica perante a tradição tanto racionalista quanto empirista, e propôs uma reforma científica que buscasse unir essas duas concepções que, na época, estavam enraizadas por erros.

Por outro lado, Rossi também procura enfatizar a distinção que Bacon faz entre ídolos inatos e adquiridos de modo a evidenciar que o filósofo considerou certas especulações teóricas anteriores a observação. Deste modo, os ídolos inatos são aqueles inerentes à natureza humana, dos quais não pode desfazer, sendo eles os ídolos da tribo, da caverna e do foro; enquanto que os ídolos adquiridos são as teorias filosóficas especulativas e as falsas demonstrações empíricas da tradição, chamados de ídolos do teatro. Os primeiros apenas podem ser identificados para que se tenha consciência de sua força, ao passo que os adventícios podem ser, com muita dificuldade, eliminados (ROSSI, 2006, p. 341-342). A explicação de Rossi aponta, assim, certa consciência de Bacon sobre esses "componentes teóricos", como os chama Popper, presentes no intelecto humano, antecedentes a observação.

Por outro lado, Horton, em seu artigo "In Defenceof Francis Bacon: A CriticismoftheCritics of the Inductive Method", considera que a purificação da mente parece ser mais um ideal do que algo a ser realmente feito ou possível de ser feito, justamente porque Bacon tinha consciência da presença dos ídolos inatos. Assim, o grau de sistematização do método de Bacon é visto por Horton como uma medida que busca eliminar os erros que constantemente podem surgir a partir de falhas do intelecto (HORTON, 1973, p. 265-266). Como os ídolos inatos não podem ser eliminados fica a cargo da etapa experimental de teste da teoria a correção dos erros que emergiram durante a interpretação dos dados pelo intelecto.

Considerando-se que as críticas quesão feitas a interpretação de Popper acerca do antiteoricismo de Bacon, procuram enfatizar que há ídolos inatos e adquiridos, precisamos esclarecer o papel dos ídolos inatos na investigação da ciência. Os ídolos inatos tem papel interpretativo para Bacon?

Nas obras O Progresso do Conhecimento (2007, p. 198-199) e Novum Organum (1999, p. 40), Bacon afirma que o intelecto humano é como um espelho que reflete desigualmente a natureza, isto é, um cientista não precavido dos perigos de não controlar a mente, observará a natureza incorrendo em erros. Ora, se existem ídolos inatos, ou falácias e falsas aparências que pertencem à natureza humana e são condição vital (BACON, 2007, p. 201), que precisam ser administrados, claro está que Bacon percebeu o papel interpretativo destes a ponto de propor cautela ao cientista por considerá-los danosos. O que está em jogo, porém, é a maneira como o filósofo se posiciona negativamente diante da influência desses componentes mentais, e, assim, estabelece a própria indução como meio para controlá-los (SOTO, 2017, p. 135), ao contrário de Popper que os julga como a etapa inicial do método científico, atribuindo-lhes o papel de hipóteses ou conjecturas (POPPER, 2013, p. 244). Fica evidente, dessa forma, que para Bacon e Popper há certas conjecturas que antecedem a observação, porém elas vistas de formas distintas pelosdois filósofos.

Apesar da dispensabilidade dos ídolos em se tratando do método baconiano, a consciência desses refuta a ideia de que Bacon acreditava ser possível uma mente vazia, tal como julga Popper em $O$ Mito do Contexto (2009, p. 148). Daí que não se pode considerá-lo um empirista ingênuo.

Outro aspecto a ser considerado, que permite colocar em dúvida a interpretação de Popper sobre o

${ }^{4}$ Em O Mito do Contexto (2009), Popper afirma que não há observação pura, que sempre se opera com teorias (componente teórico), mesmo que seja de forma inconsciente. Ao trazer essa citação de Popper, queremos afirmar que os ídolos constituem-se como componentes teóricos. 
suposto posicionamento antiteórico de Bacon, diz respeito ao famoso aforismo XCV, do Livro I do NovumOrganum, no qual Bacon buscou uma mediação entre as correntes "empirista" e "racionalista" presentes até sua época. Rossi segue essa linha interpretativa quando enfatiza que Bacon é contra aqueles que se atêm a colher os fatos da experiência sem uma teoria que os guie, criticando diretamente a leitura de Popper.

Bacon está longe de dividir os homens em duas categorias, a dos open minded e a dos superstitious, inventadas pela mente fértil de Popper e de seus discípulos. O que Bacon faz é dividi-los em duas classes, a dos Empíricos ou acumuladores e consumidores de fatos que se assemelham às formigas; e a dos Racionais ou elaboradores de teorias retiradas apenas do interior da própria mente, que se assemelham às aranhas. A atividade verdadeira (opificium) da filosofia não repousa apenas nas forças da mente, nem consiste em obter material da história natural e dos experimentos para conservá-lo na memória intacto, do jeito que o encontra. Como as abelhas, a verdadeira filosofia segue o caminho do meio: retira seu material das flores dos campos e dos jardins, mas o transforma e o digere com o intelecto (ROSSI, 2006, p. 33-34).

Rossi se opõe, assim, a uma passagem de Popper em que o mesmo salienta haver em Bacon uma divisão do homem em duas partes: uma superior, que se ocupa com a verdade e com o conhecimento (episteme), e outra, inferior, que é ordinária e fonte de toda ignorância (doxa). A primeira, então, é a parte superhumana e a segunda humana (POPPER, 2008, p. 44-45). O que Bacon faz, na realidade, é identificar e denunciar duas concepções tradicionais de ciência, a que tende ao empirismo e a que tende ao racionalismo, para propor uma nova que busca unir o que há de melhor naquelas.

A respeito dessa questão, outros autores seguem o mesmo raciocínio de Rossi. É o caso de Barreto \& Moreira (1993, p. 50) que consideram que Bacon"defende a necessidade de que o cientista se afaste do empirismo radical e do racionalismo exagerado", e de Zaterka (2003, p. 110), ao afirmar que, para o filósofo, o âmbito epistemológico contém "relações entre teoria/prática [...] que tem por objetivo unir os conhecimentos racional e empírico, criando uma ciência ativa".

Horton, por sua vez,ao analisar o mesmo aforismo (XCV) comenta que Bacon é compreendido como pertencente à classe dos empíricos, mas que não pode ser julgado como um puro empirista, visto que suas críticas se direcionaram também a essa classe de intelectuais. Acrescenta, ainda, que no aforismo LII, do Livro II, sãosugeridas correções a indução, isto é, derivação de novos experimentos dos axiomas formulados a partir dos dados registrados nas tábuas, que são os próprios testes da teoria.

Dessa forma, o que Bacon propõe é um processo contínuo de testes de teorias, resultando sempre em novos experimentos das mesmas, como advogam os defensores da abordagem dedutivista (HORTON, 1973, p. 256). Para fortalecer sua argumentação, Horton apresenta uma passagem do aforismo LXXXII, do Livro I do Novum Organum, em que se faz menção a um archote, ou a uma luz, que é capaz de iluminar o caminho a ser seguido, iniciando por uma experiência organizada capaz de proporcionar a criação de axiomas e, a partir destes, para novos experimentos.

O que Horton sugere é que o "archote", apesar de ser lido por ele mesmo como sendo o próprio método indutivo, pode ser entendido como uma ideia capaz de dar luz ao processo de construção do conhecimento científico (HORTON, 1973, p. 257), isto é, de dar um norte ao cientista que coletará dados observacionais da natureza. E acrescenta quenos aforismos CIII e CVI, do Livro I, Bacon indica o papel da "nova luz" (o axioma) que precede a uma exaustiva coleta de fatos. Essa etapa a que Horton se refere diz respeito ao método baconiano propriamente dito.

Assim, de acordo com a argumentação dos estudiosos da obra de Bacon, ele não é um empirista 
ingênuo. Apesar de alguns aforismos parecerem dar razão às interpretações popperianas, outros nos permitem dizer que o filósofo inglês não é um antiteoricista, na medida em que mostram como ele entende o papel da razão e da teoria no processo de construção da ciência, mesmo que esta esteja fadada a pensar as observações perceptuais, controlando-as da melhor maneira possível.

\section{Considerações Finais}

Chegar a uma conclusão sobre a interpretação de Popper acerca da teoria da ciência de Bacon, no sentido de aceitá-la ou então, rechaçá-la, não é uma tarefa simples, porém acreditamos que alcançamos conclusões significativas que põem em questão essa interpretação. Mas, é importante, primeiramente, pontuarmos que há certos aforismos do Novum Organum, que quando lidos isoladamente possibilitam a leitura de Popper. Nesse sentido, Bacon pode ser visto como um antiteoricista se tomarmos como pressuposto sua recomendação de que os ídolos devem ser expurgados da mente para que possamos conhecer as formas da natureza, bem como, sua defesa do método indutivo, que tem como ponto de partida a observação perceptual dos fatos naturais e seu registro nas tábulas. Entretanto, isso significa dizer que Bacon é um puro empirista, que não se atentou aos problemas que a indução e a observação carregam consigo.

Como mostramos acima, Bacon sabia do problema, e até mesmo da impossibilidade, de retirar da mente o que chamou de ídolos e, por isso, propôs um método sistemático e rigoroso que tem como propósito corrigir os erros que os ídolos inatos podem causar. O próprio Horton nos mostra que essa ideia de purificação da mente se revela mais como um ideal do que como uma realidade possível. Visto dessa perspectiva, Bacon não se mostra como um puro empirista.

De fato, há em seus escritos uma defesa da observação como ponto de partida da ciência, e é aqui que Popper centra sua crítica e vê tal ideia como manifestação de seu observacionismo. Mas a sua preocupação não era propor um método que supervalorizasse a observação, nem tampouco a razão, e sim fundar um procedimento que buscasse fugir do autoritarismo da tradição empírica e racional.

Assim, propõe seu método que se inicia pela observação, mas que precisa da teorização para que o processo prossiga. Não há em Bacon uma hostilização "a todas as formas de pensamento teórico" como apregoa Popper (POPPER, 2009, p. 145), mas sim, a defesa de uma teoria que resulta de uma interpretação de fatos recolhidos pelos sentidos, que muito provavelmente erram, e de uma corroboração de testes experimentais, ou seja, uma teoria com certo grau de segurança.

Concluímos, assim, que Bacon não pode ser considerado como defensor de uma observação pura, própria do empirismo ingênuo. Suas reflexões também se dirigiam aos problemas que a concepção empirista apresentava, prova disso é a crítica apresentada no aforismo CXV do Livro de Novum Organum. Ora, se Bacon não é ingênuo, então ele não é um antiteoricista, uma vez que não defendeu um método que supervaloriza a observação, mas que busca colocá-la no mesmo grau de importância da razão. Ambas isoladas podem levar a conhecimentos duvidosos, mas juntas podem produzir conhecimentos científicos confiáveis.

\section{Referências}

BACON, Francis. Novum Organum ou verdadeiras Indicações acerca da Interpretação da Natureza. São Paulo: Editora Abril Cultura, 1999. 
. O Progresso do Conhecimento. São Paulo: Editora UNESP, 2007.

BARRETO, J.A. E.; MOREIRA, R. V. O. O Problema da Indução: O Cisne Negro Existe. Fortaleza: Edição dos Autores, 1993.

DIAS, E. A. Popper e as Ciências Humanas. Belém: EDUFPA, 1992.

HORTON, M. "In Defenceof Francis Bacon: A Criticism of the Critics of the Inductive Method". Studies in History and Philosophy of Science, 4(2), 1973, pp. 241-278.

POPPER, K. R.A Lógica da Pesquisa Científica. $2^{\text {a }}$ ed. São Paulo: Editora Cultrix, 2013. . Conjecturas e Refutações. Brasília: Editora da UNB, 2008.

. O Mito do Contexto: Em Defesa da Ciência e da Racionalidade. Lisboa: Ed. 70, 2009.

ROSSI, Paolo. Francis Bacon: da Magia à Ciência. Londrina: Eduel; Curitiba: Editora da UFPR, 2006.

SOTO, D. P. Francis Bacon: de la reforma del saber a "imperio humano sobre el universo. Una lectura a partir del concepto de Forma". Tese (DoutoradoemFilosofia) - Facultad de Filosofía y Letras, Universidad Santo Tomás. Bogotá: p. 366, 2017.

ZATERKA, Luciana. "Alguns Aspectos da Filosofia da natureza de Francis Bacon”. In: A Filosofia Experimental na Inglaterra do Século XVII: Francis Bacon e Robert Boyle. São Paulo: Associação Editorial Humanitas, 2003.

Artigo recebido em: 27 de outubro de 2019

Artigo aceito em: 25 de dezembro de 2019 